Елинская Я. А.

Ya. A. Yelinskaya

КУЛЬТУРА НЕОШАМАНИЗМА В РУССКОМ СЕГМЕНТЕ

ИНТЕРНЕТА: КОММУНИКАТИВНЫЙ И ФУНКЦИОНАЛЬНЫЙ АСПЕКТЫ

\title{
THE CULTURE OF NEOSHAMANISM IN THE RUSSIAN SEGMENT INTERNET: COMMUNICATIVE AND FUNCTIONAL ASPECTS
}

Елинская Янина Алексеевна - директор Сибирского института практической психологии, педагогики и социальной работы (Россия, Новосибирск); 630009, г. Новосибирск, ул. Никитина, 20; тел.: + 7 (903) 93453-04. E-mail: yanina55555@mail.ru.

Ms. Yanina A. Yelinskaya - director of Siberian institute of practical psychology, pedagogy and social work (Russia, Novosibirsk); 630009, Novosibirsk, 20 Nikitina str.; tel.: + 7 (903) 934-53-04. E-mail: yanina55555@mail.ru.

Аннотация. В статье исследуется репрезентация в российском Интернете культуры неошаманизма как специфического феномена современной религиозной идентичности. На основе информационнокоммуникативного подхода анализируются неошаманские сайты и сообщества в социальных сетях (на примере сети «ВКонтакте») и показатели их аудитории. Особое внимание уделено воздействию используемых коммуникативных кодов на репрезентацию неошаманизма и его адаптацию к потребностям современного человека. Исследование показало, что продвижение неошаманизма в интернете ориентировано на универсального потребителя «духовных услуг», находящегося в поиске альтернативных мировоззрений. Функция неошаманских сообществ в социальных сетях заключается в окружении пользователя виртуальными знаками пребывания в «шаманской вселенной».

Summary. The article deals with the representation of neoshamanism culture in the Russian Internet as a specific phenomenon of modern religious identity. On the basis of information-communicative approach the neoshaman websites and communities in social media (on the example of «Vkontakte») and indicators of their audience are analyzed. Special attention is paid to the impact of the communicative codes used on the representation of neoshamanism and its adaptation to the needs of modern man. The study showed that the promotion of neoshamanism on the Internet is focused on the universal consumer of «spiritual services», which is in search of alternative worldviews. Function of the neoshaman communities in social media lies in the user's environment with virtual signs stay in the «shamanic universe».

Ключевые слова: неошаманизм, идентичность, социальная сеть, репрезентация, код, контент, мотиватор, шаманская вселенная.

Key words: neoshamanism, identity, social media, representation, code, content, motivator, shamanic universe.

УДК 008

Неошаманизм представляет собой характерный феномен современной религиозной культуры, активно пользующийся новыми медиа и широко представленный в сети Интернет. Под понятием «неошаманизм» понимаются различные формы возрождения (или имитации) традиционных шаманских практик в условиях современной культуры. Целью данной статьи является рассмотрение особенностей репрезентации культуры российского неошаманизма в Интернете. Особое внимание сосредоточено на социальной сети «ВКонтакте» (Далее - ВК).

Методологической базой исследования выступает теория информационнокоммуникативной культуры, согласно которой изменения в технологиях коммуникации оказывают решающее воздействие на информационное содержание культуры, а бытие общества сегодня определяется «новыми формами включённости в коммуникативные сети» [2, 244]. С этой точки зрения особый интерес вызывают следующие аспекты репрезентации неошаманизма в Интернете 
Елинская Я. А.

КУЛЬТУРА НЕОШАМАНИЗМА В РУССКОМ СЕГМЕНТЕ ИНТЕРНЕТА: КОММУНИКАТИВНЫЙ И ФУНКЦИОНАЛЬНЫЙ АСПЕКТЫ

и социальных сетях: а) Каковы функции этой репрезентации? б) На кого она направлена? в) Какие средства (коды) используются и какую форму они придают культуре неошаманизма?

В отличие от традиционного шаманизма, существовавшего в условиях родоплеменной культуры с высокой степенью однородности и устойчивости социальных связей, неошаманизм действует в контексте множественных культурных идентичностей, подвижных социальных связей и ролей. В этом отношении неошаманизм относится к разряду внеконфессиональных исповеданий, которые предполагают «духовно-ориентированный» тип религиозной идентичности, свободный от жёсткой привязки к определённой конфессии $[3,76]$.

Ориентация на такой тип духовно-религиозной идентичности обусловливает открытый для культурной коммуникации и обмена характер неошаманизма. «Новые шаманы» обращаются к «всеядному» жителю современного города, испытывающему потребность в обогащении своих психологических переживаний [1]. Отсюда следует нехарактерная для традиционного шаманизма многословность - неошаман не только практикует камлания и ритуалы, но и подробно описывает и «продвигает» их, производит и распространяет комментарии, призванные перевести шаманский опыт на язык современного потребителя «духовных услуг». Для этой цели рекрутируются различные каналы (телевидение, печать, сайты, социальные сети) и герменевтические коды, транслирующие шаманское мировоззрение (научная и псевдонаучная терминология, психоанализ и психотренинг, эзотерика и альтернативная медицина, художественные языки).

Использование Интернета становится коммерческой необходимостью в продвижении шаманских услуг и мероприятий, так как современный шаманизм стал частью коммерческой индустрии альтернативной медицины, парапсихологических тренингов, шоу-бизнеса и «мистического» туризма.

Формат интернет-продвижения унифицирует представление шаманизма на сайтах и в социальных сетях, организуя его различные элементы по шаблонам промостраницы, рекламного объявления или новости. Так, например, сайт шамана Дунгура Эвея содержит характерные разделы: дескрипторы, включающие заголовок и подзаголовок («Долина Белого шамана - проведение семинаров и тренингов шаманом Горного Алтая»); «шапка» представляет основные страницы сайта («Семинары и тренинги», «Услуги», «Отзывы», «Контакты»); меню включает разделы «О себе», «Перечень услуг», «Этнолавка», «Частые вопросы» и т.д. (см. прим. 1).

Реклама открытого занятия «Дыхание силы - погружение в шаманское пространство» московского шамана Марка Гусляка содержит перечисление его статусов («родовой шаман, целитель, горловой певец... один из 13 шаманов Международного фестиваля “Зов Тринадцати Шаманов” в Тыве»), программу занятий («резонаторная сонастройка при помощи звука», «мощное очищение всей энергетической системы», «углублённая практика шаманского дыхания на ощущение всех энергоцентров», «работа с верхним, средним и нижним мирами» и т.д.), контактные данные и ссылку на страницу «Дом Шамана Magenta» (см. прим. 2).

Ясно, что дизайн сайта разрабатывается специалистом по стандартной схеме с учётом требований «юзабилити» и поисковой оптимизации, а объявление в социальной сети создаётся в соответствии с форматом быстрого просмотра ленты. Но при этом происходит трансформация самого (нео)шаманского опыта: он структурируется по рубрикам с эклектичной по содержанию, но почти мгновенной идентификачией для пользователя сети: «психологический тренинг, включающий общение с Духами», «календарный обряд с настройкой на вибрации Вселенной», «шаманские амулеты и талисманы на успех в бизнесе» и т.п. Шаманский опыт, несмотря на его инородность в современной цивилизации, оказывается, успешно распределён по рубрикам в сознании современного человека. Эти рубрики соответствуют основным ценностям современного индивида: семейные и любовные отношения, материальное благополучие, карьерный рост, исполнение желаний и реализация планов.

Практическая ориентированность неошаманизма, тем не менее, предполагает акцентирование его экзотичности и уникальности по отношению к стандартным для технологической цивилизации способам деятельности. Неошаманизм, являясь частью глобальной культуры New Age, продвигает и репрезентирует себя как духовную альтернативу инструментальным и рациональным 


\section{Учёные записки}

Комсомольского-на-Амуре государственного технического университета

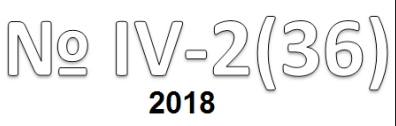

технологиям современности. Отвечая на потребность в духовной экзотике и гармонии с природой, он предлагает модернизированный вариант анимизма: веру в одушевлённость природы, гармонизацию повседневного времени с природными циклами, взаимодействие с «энергиями» природных мест («мест силы») и магических артефактов.

Именно это содержание наполняет страницы неошаманских сайтов и групп в социальных сетях. На сайте «Самопознание.ru» шаманки Айдана Алтын-Суу и Туя Самдан предлагают посетить «Шаманскую усадьбу» на Горном Алтае, описывая достоинства этого места: «Энергетика этого места особенная. Неспроста рядом находится поляна, которая раньше использовалась шаманами для проведения своих ритуалов... Это одна из причин, по которой здесь удивительно плодотворно проходят семинары и тренинги. Природные и ландшафтные особенности усадьбы и её окрестностей... создают все необходимые условия для достижения поставленных целей» (см. прим. 3). Визуальное содержание страниц сайтов и групп в соцсетях заполнено образами природных ландшафтов, архаических шаманских костюмов, амулетов и идолов, выполненных в соответствующей стилистике народов-шаманистов.

Сосредоточимся на репрезентации неошаманизма в социальной сети ВК, обосновав выбор популярностью её среди российских пользователей и возможностью анализировать статистику сообществ (см. прим. 4). В сети ВК значительное количество групп, в названиях которых встречается слово «шаманизм» или «шаман». В их число входят открытые и закрытые группы различной тематики, страницы общественных организаций или культурных центров. Конечно, не все из них имеют отношение к шаманизму, а могут только иметь слово «шаман» в названии, они также могут быть неактивными или насчитывать не более 100 человек.

Тем не менее, большая часть этого массива связана с тематикой шаманизма и неошаманским мировоззрением. В названиях групп встречаются характерные связки: «Тропою шамана», «Дух шамана», «Саморазвитие: магия, руны, шаманизм», «Космоэнергетика, биоэнергетика, шаманизм, эзотерика», «Городской шаманизм и экстремальные практики» и т.д. Количество участников групп варьируется в диапазоне от 100000 до нескольких десятков человек.

На примере 18 сообществ различной степени популярности был проанализирован половозрастной состав их участников (оценка проводилась с 7 по 17 апреля 2017 г.). Половая дифференциация участников неошаманских сообществ (40,5 \% мужчин и 59,5 \% женщин) почти дублирует данные о половых различиях активных авторов сети ВК (43,7 \% мужчин, 56,3 \% женщин (см. прим. 5)) и показатели российского населения в целом (46 \% мужчин, 54 \% женщин (см. прим. 6)). Можно лишь говорить о некотором перевесе женской аудитории в общей совокупности исследованных неошаманских групп - доля женщин в ней в среднем на 3 \% больше, чем у общей аудитории ВК и на 5 \% больше, чем в статистике российского населения (см. табл. 1).

Нельзя чётко разделить, в каких типах сообществ доминирует женская аудитория, а в каких - мужская. Как в «философских» группах, так и в группах, продвигающих услуги конкретных неошаманов, могут преобладать как мужчины, так и женщины. Видимо, гендерные «перевесы» зависят от случайных факторов продвижения конкретного сообщества и сложившейся клиентуры отдельного шамана.

Таблица 1

Половой состав аудитории неошаманских сообществ в социальной сети «ВКонтакте»

\begin{tabular}{|l|l|c|c|c|}
\hline \multicolumn{1}{|c|}{ Сообщество } & \multicolumn{1}{|c|}{$\begin{array}{c}\text { Тип } \\
\text { сообщества }\end{array}$} & $\begin{array}{c}\text { Общее } \\
\text { количество } \\
\text { участников }\end{array}$ & $\begin{array}{c}\text { Мужчины, } \\
\text { (\%) }\end{array}$ & $\begin{array}{c}\text { Женщины, } \\
\text { (\%) }\end{array}$ \\
\hline Шёпот шамана & философия & 103275 & 53,1 & 46,9 \\
\hline Тропою шамана & философия & 92881 & 40,2 & 59,8 \\
\hline Шаман Ка & открытая группа & 20916 & 23,0 & 77,0 \\
\hline
\end{tabular}


Елинская Я. А.

КУЛЬТУРА НЕОШАМАНИЗМА В РУССКОМ СЕГМЕНТЕ ИНТЕРНЕТА: КОММУНИКАТИВНЫЙ И ФУНКЦИОНАЛЬНЫЙ АСПЕКТЫ

Продолжение таблицы 1

\begin{tabular}{|l|l|c|c|c|}
\hline \multicolumn{1}{|c|}{ Сообщество } & \multicolumn{1}{|c|}{$\begin{array}{c}\text { Тип } \\
\text { сообщества }\end{array}$} & $\begin{array}{c}\text { Общее } \\
\text { количество } \\
\text { участников }\end{array}$ & $\begin{array}{c}\text { Мужчины, } \\
(\%)\end{array}$ & $\begin{array}{c}\text { Женщины, } \\
\text { (\%) }\end{array}$ \\
\hline Мудрость шаманов Сибири & общественный деятель & 12789 & 38,4 & 61,6 \\
\hline $\begin{array}{l}\text { Дом шамана. Пространство } \\
\text { духа }\end{array}$ & открытая группа & 7982 & 47,6 & 52,4 \\
\hline ShamТеrra & открытая группа & 3289 & 41,3 & 58,7 \\
\hline Дух шамана & культурный центр & 3183 & 49,6 & 50,4 \\
\hline Зов духа. Шаманский опыт & открытая группа & 3044 & 38,2 & 61,8 \\
\hline МРОШ Тэнгэри & открытая группа & 2891 & 33,3 & 66,7 \\
\hline Шаманизм (Живой Космос) & открытая группа & 1543 & 51,2 & 48,8 \\
\hline Зов 13 шаманов & мероприятие & 1510 & 39,7 & 60,3 \\
\hline Дмитрий Ильин, шаман, це- \\
литель & открытая группа & 958 & 36,4 & 63,6 \\
\hline Дом шамана. Обучение и \\
помощь в Новосибирске & открытая группа & 731 & 23,1 & 76,9 \\
\hline Шаман / Экстрасенс & открытая группа & 713 & 60,0 & 40,0 \\
\hline Шаман-Тигр Ай-Хаан & открытая группа & 636 & 46,4 & 53,6 \\
\hline Дом шамана в Красноярске & открытая группа & 389 & 17,7 & 82,3 \\
\hline МРОШ «Байкал» & открытая группа & 307 & 37,1 & 62,9 \\
\hline МРОШ «Дархан Тэнгэри» & открытая группа & 168 & 51,8 & 48,2 \\
\hline \multicolumn{2}{|l|}{ Среднее значение } & 40,5 & 59,5 \\
\hline
\end{tabular}

В возрастной структуре аудитории неошаманских сообществ доминирует группа от 25 до 34 лет (37,7 \%), что можно считать характерным для аудитории ВК вообще. Но на втором месте по численности располагается не более молодая группа - от 18 до 25 лет (11\%), а более старшая от 35 до 44 лет (28,2 \%), то есть заметно преобладание взрослой аудитории (см. рис. 1).

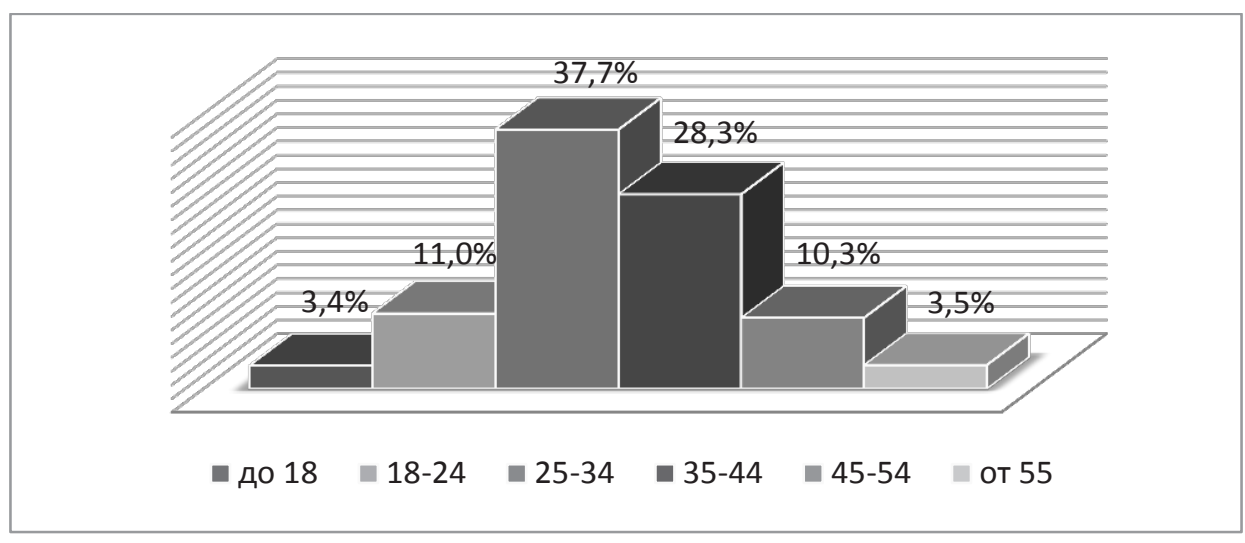

Рис. 1. Возрастной состав аудитории неошаманских сообществ в социальной сети «ВКонтакте»

Контент, заполняющий страницы неошаманских сообществ, несмотря на их большое число и разные функции, достаточно однообразен. Информация, как правило, представляет собой мозаичное взаимодействие письменных текстов, визуальных образов и аудиосообщений (музыкальных произведений). 


\section{Учёные записки}

Комсомольского-на-Амуре государственного технического университета

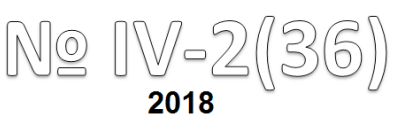

Во всём корпусе текстовых сообщений можно выделить ряд содержательных блоков, которые обозначим следующим образом: культурно-просветительский - изложение основ шаманской мифологии, ссылки и фрагменты научных исследований шаманизма, описание атрибутов шаманской практики; рекламный - объявления об услугах или мероприятиях; эзотерикопрагматический - советы и рецепты практической деятельности (гороскопы, кулинарные рецепты, инструкции по медитации, камланию и т.п.); мотиваторы - «глубокомысленные» изречения и цитаты.

Последний блок можно считать самым распространённым и доминирующим, так как именно этот контент позволяет поддерживать активность сообщества, являясь популярным объектом «репостов» и комментариев. «Глубокомысленные» мотиваторы являются одним из характерных жанров в социальных медиа. Как правило, подлинность таких высказываний не выдерживает проверки; содержание же часто бессмысленно либо банально, но оформлено в виде высокопарных афоризмов.

В неошаманских группах в качестве цитируемых «авторов» выступают духовные учителя прошлого и настоящего времени. Очень немногие из них имеют отношение к шаманизму (Карлос Кастанеда), но большинство имён ассоциируется с альтернативной западному разуму мудростью: Будда, Далай-Лама, Махатма Ганди, Гегам (Армен Гегамян), Экхарт Толле, Сумиран и др.; могут встречаться и вполне светские персонажи: Рэй Брэдбери, Альберт Эйнштейн. Достаточно часты и анонимные афоризмы, подкреплённые только каким-либо изображением. Функция таких изречений в шаманских и в целом «мистических» сообществах заключается не в трансляции целостного мировоззрения или психологических установок, а скорее в том, чтобы служить знаками альтернативной духовности и симулякрами личностного развития, ни к чему определённому не обязывающего.

Такую же функцию маркера особой духовности выполняет визуальный контент неошаманских сообществ. «Мудрым» изречениям должны придать вес прилагаемые фотографии и картины, как правило, имеющие более близкие ассоциации с шаманизмом. Среди распространённых мотивов встречаются образы шаманов различной этнокультурной принадлежности, изображения визионерского опыта, тотемические образы (волк, медведь, ворон, лошадь), образы природы и человека в контексте природы. Популярны работы художников, пишущих на шаманские темы: Владимира Никишина, Тимофея Степанова, Азата Миннекаева, Луиса Тамани, Пабло Амаринго, Сьюзен Седдон Булет, Норваля Мориссо. Активно используется искусство художников, работающих в стиле visionary art - визуализации опыта изменённого состояния сознания (Алекс Грэй, Камерон Грэй, Андрю Гонзалес и др.). В целом визуальный стиль неошаманских групп в ВК можно определить как синтез этнографических, экологических и психоделических мотивов.

Аудиоконтент неошаманских сообществ заполнен музыкальными произведениями различных направлений этнической музыки, ассоциирующейся с шаманистскими культурами. Это в основном сибирские, северноевропейские и американские музыкальные традиции. Аудиосопровождение ориентировано на то, чтобы воспроизводить в звуковой форме состояние шаманского транса, погружение в «шаманскую вселенную». Для этого используется музыка, исполняемая на характерных «шаманских» инструментах: бубне, варгане (хомус), традиционных щипковых инструментах, а также и горловым пением. Среди популярных исполнителей, ориентирующихся на сибирские шаманистские культуры, следует назвать таких музыкантов, как Конгар-Оол Ондар, Николай, Владимир Каруев (сценический псевдоним - Okna Tsahan Zam), Тюргэн Кам, тувинский ансамбль «Хуун-Хуур-Ту». Популярны в неошаманских сообществах музыкальные коллективы, исполняющие скандинавский neofolk и ritual ambient: Wardruna, Heilung, GaldrareyniR и др.

Для музыкальной формы неошаманизма характерно взаимодействие с современными музыкальными направлениями: электронной музыкой, джазом, роком и т.д. К примеру, тувинский мастер горлового пения Конгар-Оол Ондар участвовал в записи нескольких альбомов американской группы Bela Fleck and the Flecktones; Николай Ооржак записал совместный альбом с московским джаз-коллективом Alissid Jazz. Такое взаимодействие шаманской традиции и современной 
Елинская Я. А.

КУЛЬТУРА НЕОШАМАНИЗМА В РУССКОМ СЕГМЕНТЕ ИНТЕРНЕТА: КОММУНИКАТИВНЫЙ И ФУНКЦИОНАЛЬНЫЙ АСПЕКТЫ

музыкальной культуры основано на их общей ориентации на воспроизведение состояния транса при опоре на метроритмическую пульсацию.

Понятие транса можно распространить и на другие элементы репрезентации неошаманизма в социальных сетях. «Глубокомысленные» мотиваторы не претендуют на роль психологических рецептов личностного саморазвития, скорее, выступают своеобразными магическими заклинаниями, создающими эффект символического управления реальностью. Психоделические картины воспроизводят на экране визуальный образ «шаманской вселенной». В этом смысле само пребывание в социальных сетях можно приравнять к шаманскому трансу в его рафинированном, современном варианте.

Итак, представленность культуры неошаманизма в русском сегменте Интернета показывает, во-первых, его ориентацию на универсального потребителя «духовных услуг». Как показывает анализ сообществ в социальной сети ВК, среди лиц, интересующихся шаманизмом, женщины и мужчины представлены в равной степени, а основной возраст - средний (25-45 лет).

Во-вторых, неошаманизм представляет собой результат адаптации шаманской культуры к особенностям современной цивилизации и современного человека - в Интернете она структурируется по принципам сайтостроения и SMM-продвижения и переводится на язык секулярных ценностей-потребностей атомизированного индивида. Видимо, ведущей потребностью, заставляющей проявлять интерес к культуре неошаманизма, является стремление к духовной альтернативе, обещающей целостность, гармонию личности и природы, способность руководить своей судьбой.

В-третьих, анализ неошаманских сообществ в сети ВК вскрывает ещё один важный аспект - участие в них позволяет интернет-потребителю окружить своё пребывание в сети виртуальными знаками шаманского опыта: заклинаниями-мотиваторами, психоделическими образами и медитативно-ритуальной звуковой дорожкой. Вопрос о том, скрывается ли за этими знаками какая-либо вневиртуальная реальность, не имеет смысла, так как речь идёт о символах, обретающих реальность в процессе виртуальной коммуникации.

\section{ЛИТЕРАТУРА}

1. Иващенко, Я. С. Аксиология современного шаманизма в Хабаровском крае / Я. С. Иващенко, Я. А. Елинская // Международный журнал исследований культуры. - 2016. - № 2(23). - С. 85-94.

2. Матвеева, Ю. А. Информационно-коммуникативная культура как основная характеристика современного общества / Ю. А. Матвеева // Вестник Бурятского государственного университета. - 2010. - № 6. - С. 243 247.

3. Пронина, Т. С. Типологизация новых религиозных движений на основе ценностей и потребностей Т. С. Пронина, Ю. С. Федотов, Е. Ю. Федотова // Социологические исследования. - 2018. - № 1. - С. 73-82.

\section{ПРИМЕЧАНИЯ}

1. Долина белого шамана. Режим доступа: http://dolinabelogoshamana.ru/excurs.html.

2. Дом шамана Magenta - Пространство духа. Режим доступа: https://vk.com/dom.shamana.

3. Айдана Алтын Суу. Режим доступа: https://samopoznanie.ru/trainers/aydana_altyn-suu/.

4. Новрузова, Э. Социальные сети в России, лето 2017: цифры и тренды / Э. Новрузова. Режим доступа: https://www.cossa.ru/289/166387/.

5. Статистика аудитории. Популярность социальных сетей. Режим доступа: http://vawilon.ru/statistikaauditorii/.

6. Федеральная служба государственной статистики. Режим доступа: http://www.gks.ru/wps/wcm/ connect/rosstat_main/rosstat/ru/statistics/population/demography/\#. 